\title{
Leitthema
}

coloproctology 2019 $41: 101-105$

https://doi.org/10.1007/s00053-019-0351-3

(c) Springer Medizin Verlag GmbH, ein Teil von Springer Nature 2019

Pilonidal disease is common and represents a minor condition for the majority of patients. However, in some patients it can result in prolonged pain, sepsis and long periods off work and education. Many treatments have been described for this condition, which clearly demonstrates that no single procedure is completely effective. It therefore follows that failure of primary treatment as well as recurrence of the disease is inevitable to some degree after all treatment modalities [1].

The results of different treatments should be expressed as the rate of failure of the original treatment as well as the rate of recurrence after healing. Some reports do not differentiate between these two outcomes. It can sometimes be difficult to differentiate, as apparent healing may have taken place when in fact there has been a failure. It is nonetheless important that whatever treatment is carried out, the patient be no worse after treatment-whether due to failure or recurrence-than if they had not undergone the treatment in the first place. Unfortunately, this guiding principle in the treatment of this benign non-life-threatening condition is often not adhered to.

Surgeons often treat pilonidal disease using the same technique for all cases. It is known that the severity of the condition varies widely and attempts at classification have been made [2,3]. A new international classification is in the process of being developed [4]. This concept leads to the conclusion that different severities of pilonidal disease should be treated in different ways. Simple dis-

A. Senapati ${ }^{1,2}$

'St. Mark's Hospital, Harrow, London, UK

${ }^{2}$ Queen Alexandra Hospital, Portsmouth, Hants, UK

\section{Out of the midline-cleft lift, advancement and rotation procedures}

ease should be treated by surgery best suited to this, such as trephine operation [5], Bascom's pit-picking operation [6] or endoscopic pilonidal sinus treatment (EPSiT) [7]. However, there are circumstances when such operations are either not possible or have been used before and the disease has recurred. The off- or out-of-midline closures are ideally suited to these circumstances. Such situations are extensive disease, recurrence beneath a previously sutured wound and unhealed midline wounds. In other words, when there are no longer simple pits present.

The most distressing of these conditions is when there has been failure of wide excision of pilonidal disease leaving an unhealed midline wound that never heals. These wounds are treated for prolonged periods resulting in time off work, inability to hold down jobs, use of nursing resources and a diminished quality of life. These unhealed midline wounds are usually due to failure of primary treatment, although they can occur spontaneously. After they have been present for several months, they are often perceived as a recurrence by both the surgeon and the patient. These wounds are the bête noire of pilonidal surgery.

The midline wide excision, either with primary closure or with secondary healing, has been shown by several authors to have a poorer outcome than a lateral or off-midline closure. Due to the unacceptable incidence of an unhealed midline wound after these procedures, they should be abandoned [8-13].

\section{Out-of- or off-midline closures}

These include the following operations:

- Karydakis operation

- Cleft closure/lift

- Limberg flap

- Complex flaps

\section{Karydakis operation}

The best-known off-midline closure technique is the Karydakis operation ([14]; - Fig. 1). Here, a wide excision of the disease is made using an elliptical asym-

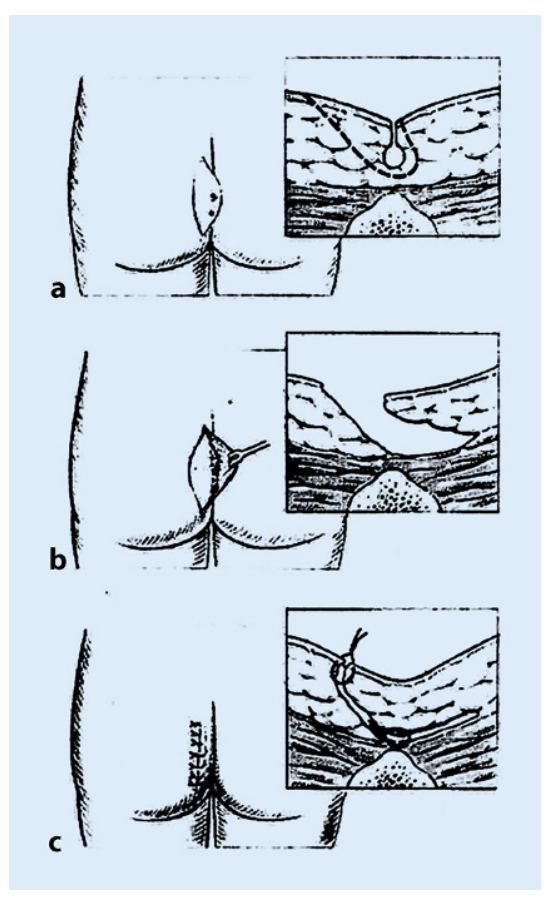

Fig. $1 \Delta$ Diagrammatic representation of the Karydakis operation. (From [26].) a Off midline excision on the left. $b$ Mobilisation of the flap from the right. c Tension free closure on the left with advancement of the flap from the right 

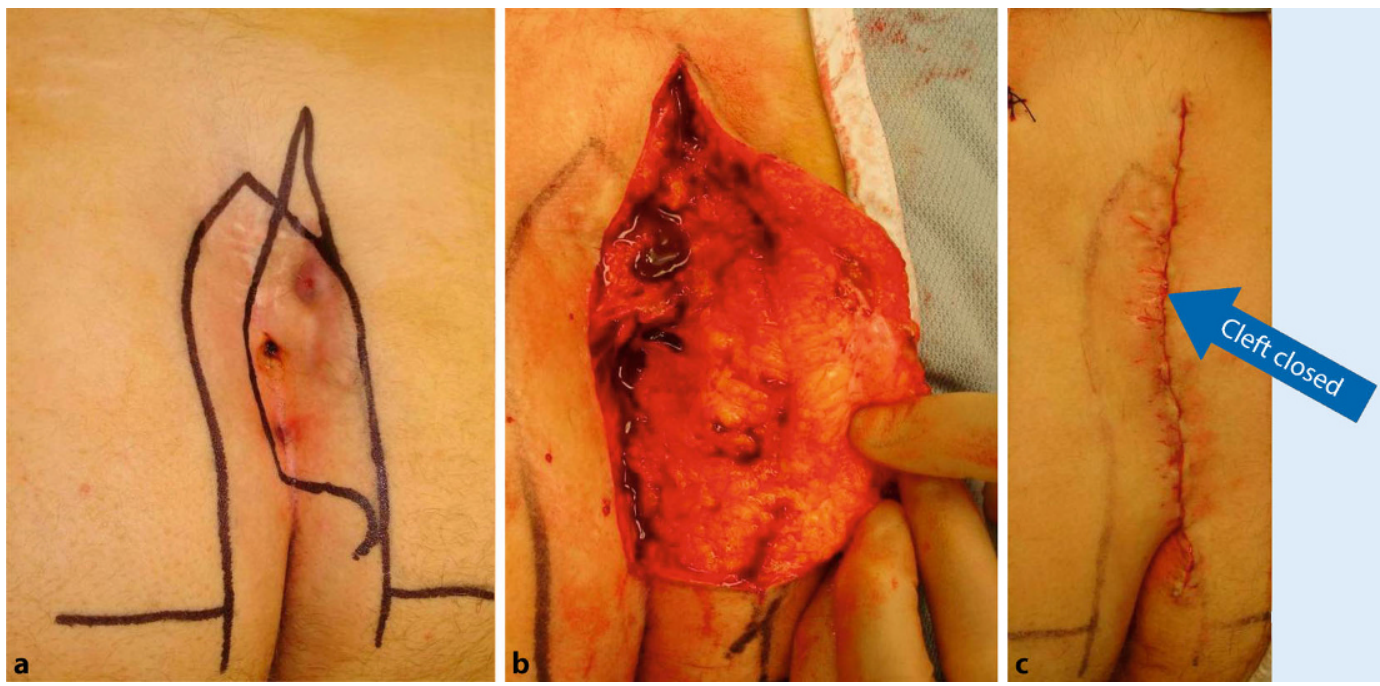

Fig. $2<$ Cleft lift operation. (From [43] with permission of Elsevier). (a) Skin markings before surgery (b) Mobilisation of the skin flap on the right before excision (c) Off midline closure after mobilisation of the skin flap from the opposite side
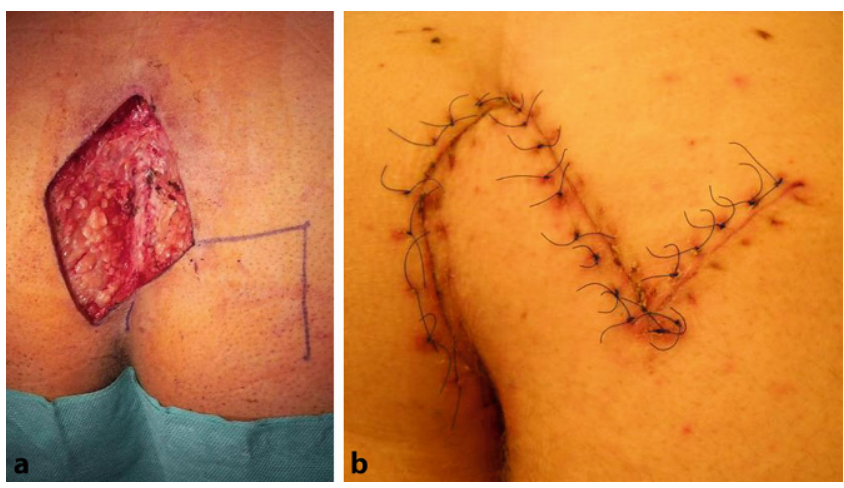

Fig. $3 \Delta$ Modified Limberg flap. a Excision of the previously marked skin and subcutaneous tissue. Note that the lower pole of excision lies $2 \mathrm{~cm}$ lateral to the midline, which creates a scar that is out of the midline at the distal end. b Closure of the Limberg flap. (from [1], Courtesy PD Dr. Sven Petersen)

metric excision down to the deep fascia. The thick flap thus created is sutured to the deep fascia and then closed to one side of the midline. A total of 7471 cases were described by Karydakis, and there has been a 2-20-year long-term followup of these patients [15]. Surgery was performed as an inpatient procedure with a hospital stay of between 1 and 3 days with a $1 \%$ recurrence rate. Many others have published their results since, with good outcomes [16-23]. The operation has also been performed as a day case [24]. Overall, recurrence rates vary from 0 to $7 \%$. In a thorough meta-analysis of all treatments, Karydakis and cleft lift were found to have the lowest recurrence rates [25].

Some trials comparing the Karydakis operation with Limberg flaps found it to be superior [27-29], with others finding it worse [30, 31]. Recurrence rates were, however, consistently low [27-29].

\section{Cleft closure/cleft lift}

This is a modification of the Karydakis operation described by Bascom $([32,33]$; - Fig. 2). Skin on each side of the natal cleft is mobilised as a fairly superficial flap with a small amount of subcutaneous tissue. The abscess cavity is not excised but instead laid open and curetted. All debris and hair is removed. The diseased skin from one side of the natal cleft is removed, the midline fat pads are closed with obliteration of the natal cleft and the skin flap sutured laterally off the midline. This procedure has the advantage that it can be performed as a day case and under local anaesthesia [33]. The cleft lift is particularly suited to treating the unhealed midline wound and results in rapid and successful healing. In a series of $150 \mathrm{pa-}$ tients, of whom $63 \%$ were treated for recurrent disease or an unhealed wound, there was a $96 \%$ success rate for healing. No patient had a major breakdown of the wound and only $5 \%$ required further surgery for recurrence [33]. Several other authors have published good results with this technique [34-39]. The recurrence rates vary from 0 to $5 \%$, although one small study of 24 patients had a $17 \%$ recurrence rate [34]. In meta-analysis the recurrence figures for this technique are the lowest reported and are similar to those of the Karydakis operation [25], compared with which it is considerably less invasive. Cleft closure/cleft lift has been compared in a randomised trial with Bascom's pit-picking procedure for fairly simple disease and has demonstrated its utility even in this setting [40]. In comparison with a Limberg flap, this procedure was found to be better in a randomised trial of 122 patients [41]. It was also found to be superior to wide excision with or without closure [42], such that the authors state that wide midline excision should not be used. It is particularly suited for the treatment of complex disease as well as an unhealed midline wound [33]. Primary wound healing occurs in 60 to $70 \%$ of patients, and most can return to return to work between 1 and 4 weeks after surgery. This and the Karydakis operation have asymmetric off-midline closures and have been demonstrated to be superior to other midline closures, which should now be 
abandoned [9, 11-13]. These operations should now be the treatment of choice for more complex disease.

\section{Limberg flap}

The Limberg flap and its variant Dufourmentel flap are the commonest complex flaps to treat pilonidal disease ([27, 30, 44, 45]; - Fig. 3). In randomised trials, the Limberg flap was found to be superior to midline closure [46, 47]. In other studies, it was found to be comparable to the Karydakis operation [48-50] and to asymmetrical elliptical excisions [51, 52]. A systematic review of the Limberg flap supported its equivalence to the Karydakis operation and its superiority over midline closure [44]. Recurrence after the operation is low at $0-4 \%$. A metaanalysis has also reported low recurrence rates [25].

The most obvious disadvantage of a Limberg flap is the cosmetic aspect. It completely obliterates the natal cleft and alters the contour of the buttocks. It scored lower than Karydakis in prospective studies [17, 29, 48].

\section{Complex flaps}

Many complex flaps have been used in the treatment of pilonidal disease. The House flap [53] has recently been described for what appears to be simple disease. Z-plasty [54-57], V-Y flaps [58-60], rhomboid flaps [61, 62] and complex plastic surgical techniques such as transverse lumbar artery perforator flap [63] are other techniques that have been used. They have also been compared with each other and with other techniques [47, 55-57]. In addition, modifications of these procedures have been described [61]. By and large, the results are no better than those obtained with the simpler flaps, as was demonstrated in a meta-analysis of treatments for pilonidal disease [25]. The Cochrane Database publications included these flaps with all off-midline closures and concluded that the latter were better than midline closures [10, 12].

Generally, the more complex the procedure the more likely the patient is to require general anaesthesia and inpatient hospital stay. Postoperative care is also more complex and there is more interruption to the patient's daily living. Undoubtedly, these procedures are also cosmetically disfiguring. Nonetheless, along with the Limberg flap, Karydakis and cleft lift, they have better outcomes than midline closure [47].

\section{Discussion}

The aim of pilonidal surgery should be to keep it as simple as possible to effectively treat the disease. Although it has been shown that recurrence after treatment is one of the major determinants for reduced quality of life [64], a simple operation that has low morbidity and a low recurrence rate should be the objective of treatment. For simple disease, the procedures that primarily deal with the pit-such as trephine, Bascom's pit-picking and EPSiT - are the most appropriate operations. They have very low morbidity, seldom make the patient worse and have recurrence rates of approximately $16 \% 5$ years following surgery, which is not low, but acceptable. The cosmetic results are very good as there is no change of contour [65]. For the off-midline closures and flaps, recurrence rates are and should be under $5 \%$ at 5 years. Any variation from this makes the morbidity and recovery from such procedures unacceptable.

As there have been many procedures described to treat pilonidal disease, it can safely be assumed that none are entirely satisfactory. They all have their advantages and disadvantages, but it seems inappropriate to treat all pilonidal disease with the same technique-treatment should be tailored to the severity of the disease. This will be facilitated by the use of a classification [4], and surgeons need to be willing to alter their technique to suit the patient.

Complex flaps, including the most commonly performed Limberg flap, have the major disadvantage of completely obliterating the natal cleft and altering the contour of the buttocks. Many patients find this unacceptable and are unwilling to consider this procedure as a first-line treatment. Modern clothing and attention to appearance coloproctology 2019 - 41:101-105

https://doi.org/10.1007/s00053-019-0351-3

(c) Springer Medizin Verlag GmbH, ein Teil

von Springer Nature 2019

\section{A. Senapati}

\section{Out of the midline-cleft lift, advancement and rotation procedures}

\section{Abstract}

Surgery is usually necessary to treat symptomatic pilonidal disease. However, some operations have the propensity to make the patient worse. Uncomplicated disease should therefore be treated by operations that excise the pits rather than excisional surgery. More complex disease, however, cannot be treated by these techniques. It has been shown in many publications that off- or out-of-midline closures have better outcomes than midline closures and wounds. Descriptions and results of these procedures are described. Midline wounds should be abandoned in favour of off-midline closures.

\section{Keywords}

Surgical procedures, operative - Recurrence . Wound healing · Surgical flaps · Pilonidal sinus

\section{Raus aus der Mittellinie - mit "cleft lift", Verschiebe- oder Rotationslappen}

\section{Zusammenfassung}

Nur mit einem chirurgischen Eingriff

kann ein Pilonidalsinus heilen. Einige Eingriffe können den Zustand des Patienten verschlechtern, deshalb sollten einfache Pilonidalsinus mit einfachen Methoden wie "pit picking" statt chirurgischer Exzision behandelt werden. Kompliziertere Sinus werden hingegen mit einfachen Verfahren nicht ausreichend versorgt. Mittlerweile ist es Allgemeinwissen, dass Verfahren außerhalb der Mittellinie bessere Ergebnisse zeigen als Mittellinienverschlüsse. Gängige Off-Midline-Verfahren werden hier dargestellt. Mittellinienverschlüsse sollten nicht mehr angewandt und stattdessen OffMidline-Verfahren eingesetzt werden.

\section{Schlüsselwörter}

Chirurgische Verfahren, operativ - Rezidiv . Wundheilung · Chirurgische Lappen . Pilonidalsinus 
make this an inappropriate choice in the first instance. This aspect of treatment is seldom addressed. When it has been, the Karydakis operation was found to be cosmetically superior to the Limberg flap $[28,29,48]$. Others have commented that some patients have an issue with the cosmetic appearance after Limberg flap [66], whereas the Karydakis operation had a cosmetic satisfaction rate of $91 \%$ in another study [67]. The cleft lift was described as having an excellent cosmetic result [33], as did a modified primary closure [68]. Studies should include the cosmetic appearance as a measure of success. In the current health care environment, patients should be offered a choice of comparable procedures based also on the cosmetic results.

\section{Conclusion}

Off-midline closure has clearly been shown to be superior to midline closure and the latter should be abandoned. It is therefore disappointing that this is still widely performed. Many have suggested that off-midline closures need to be promoted [69-71].

\section{Corresponding address}

A. Senapati
St. Mark's Hospital
HA13UJ Harrow, London, UK
asha@senapati.co.uk

\section{Compliance with ethical guidelines}

Conflict of interest A. Senapati declares that she has no competing interests.

This article does not contain any studies with human participants or animals performed by any of the authors.

\section{References}

1. Mölle, Ommer, Lange, Girona (2018) (eds) Chirurgische Proktologie, 3rd edn.

2. Guner A, Cekic AB, Boz A, Turkyilmaz S, Kucuktulu U (2016) A proposed staging system for chronic symptomatic pilonidal sinus disease and results in patients treated with stage-based approach. BMC
Surg 16(1):18. https://doi.org/10.1186/s12893016-0134-5

3. Irkörücü O (2016) Management for pilonidal disease: before you compare, use a classification system. Asian J Surg 39(4):260-261. https://doi. org/10.1016/j.asjsur.2016.04.004

4. Wysocki AP, Andersson RE, Gips M, Girgin M, Guner A, Immerman S, Kanat BH, Kayaalp C, Milone M, Petersen S, Senapati A, Tezel E, Doll D (2018) Towards a classification for sacrococcygea pilonidal disease-Berlin 2017. Pilonidal Sinus J 4(1):5-12

5. Gips M, Melki Y, Salem L, Weil R, Sulkes J (2008) Minimal surgery for pilonidal disease using trephines: description of a new technique and long-term outcomes in 1,358 patients. Dis Colon Rectum 51(11):1656-1662. https://doi.org/10. 1007/s10350-008-9329-x (discussion 1662-3)

6. Senapati A, Cripps NPJ, Thompson MR (2000) Bascom's operation in the day-surgical management of symptomatic pilonidal sinus. Br J Surg. https:// doi.org/10.1046/j.1365-2168.2000.01472.x

7. Meinero P, Stazi A, Carbone A, Fasolini F, Regusci L, La Torre M (2016) Endoscopic pilonidal sinus treatment: a prospective multicentre trial. Colorectal Dis 18(5):0164-0170. https://doi.org/ 10.1111/codi.13322

8. Allen-Mersh TG (1990) Pilonidal sinus: finding the right track for treatment. $\mathrm{Br} J$ Surg 77(2):123-132 (http://www.ncbi.nlm.nih.gov/ pubmed/2180534. Accessed December 11, 2015)

9. Petersen S, Koch R, Stelzner S, Wendlandt T-P, Ludwig K (2002) Primary closure techniques in chronic pilonidal sinus: a survey of the results of different surgical approaches. Dis Colon Rectum 45(11):1458-1467. https://doi.org/10.1097/01. DCR.0000029764.01110.5C

10. McCallum I, King PM, Bruce J (2007) Healing by primary versus secondary intention after surgical treatment for pilonidal sinus. Cochrane Database Syst Rev. https://doi.org/10.1002/14651858. CD006213.pub2

11. McCallum IJD, King PM, Bruce J (2008) Healing by primary closure versus open healing after surgery for pilonidal sinus: systematic review and metaanalysis. BMJ 336(7649):868-871. https://doi.org/ 10.1136/bmj.39517.808160.BE

12. Al-Khamis A, McCallum I, King PM, Bruce J (2010) Healing by primary versus secondary intention after surgical treatment for pilonidal sinus. Cochrane Database Syst Rev. https://doi. org/10.1002/14651858.CD006213.pub3

13. Enriquez-Navascues JM, Emparanza Jl, Alkorta M, Placer C (2014) Meta-analysis of randomized controlled trials comparing different techniques with primary closure for chronic pilonidal sinus. Tech Coloproctol 18(10):863-872. https://doi.org/ 10.1007/s10151-014-1149-5

14. Karydakis GE (1973) New approach to the problem of pilonidal sinus. Lancet 2(7843):1414-1415 (http://www.ncbi.nlm.nih. gov/pubmed/4128725. Accessed December 5, 2015)

15. Karydakis GE (1992) Easy and successful treatment of pilonidal sinus after explanation of its causative process. Aust N Z J Surg 62(5):385-389 (http:// www.ncbi.nlm.nih.gov/pubmed/1575660. Accessed December 2, 2015)

16. Keshava A, Young CJ, Rickard MJFX, Sinclair G (2007) Karydakis flap repair for sacrococcygeal pilonidal sinus disease: how important is technique? ANZ J Surg 77(3):181-183. https://doi. org/10.1111/j.1445-2197.2006.04003.x
17. Bessa SS (2007) Results of the lateral advancing flap operation (modified Karydakis procedure) for the management of pilonidal sinus disease. Dis Colon Rectum 50(11):1935-1940. https://doi.org/ 10.1007/s10350-007-9049-7

18. Kitchen PR (1996) Pilonidal sinus: experience with the Karydakis flap. $\mathrm{Br} J$ Surg 83(10):1452-1455 (http://www.ncbi.nlm.nih.gov/ pubmed/8944470. Accessed December 2, 2015)

19. Moran DC, Kavanagh DO, Adhmed I, Regan MC (2011) Excision and primary closure using the Karydakis flap for the treatment of pilonidal disease: outcomes from a single institution. World J Surg 35(8):1803-1808. https://doi.org/10.1007/ s00268-011-1138-Z

20. Patel L, Bloom A-M (1999) Prolonged delay in healing after surgical treatment of pilonidal sinus is avoidable. Colorectal Dis 1(2):107-110. https:// doi.org/10.1046/j.1463-1318.1999.00030.x

21. Keshvari A, Keramati MR, Fazeli MS, Kazemeini A, Meysamie A, Nouritaromlou MK (2015) Karydakis flap versus excision-only technique in pilonidal disease. J Surg Res 198(1):260-266. https://doi. org/10.1016/j.jss.2015.05.039

22. Sewefy AM, Hassanen A, Atyia AM, Saleh SK (2017) Karydakis flap with compressing tieover interrupted sutures without drain versus standard Karydakis for treatment of sacrococcygeal pilonidal sinus disease. Dis Colon Rectum 60(5):514-520. https://doi.org/10.1097/DCR. 0000000000000784

23. Abo-Ryia MH, Abd-AllahHS, Al-ShareefMM,Abdulrazek MM (2018) Fascio-adipo-cutaneous lateral advancement flap for treatment of pilonidal sinus: a modification of the Karydakis operation-cohort study. World J Surg 42(6):1721-1726. https://doi. org/10.1007/s00268-017-4406-8

24. Anderson JH, Yip CO, Nagabhushan JS, Connelly SJ (2008) Day-case Karydakis flap for pilonidal sinus. Dis Colon Rectum 51(1):134-138. https://doi.org/ 10.1007/s10350-007-9150-y

25. Stauffer VK, Luedi MM, Kauf $P$ et al (2018) Common surgical procedures in pilonidal sinus disease: a meta-analysis, merged data analysis, and comprehensive study on recurrence. Sci Rep 8(1):3058. https://doi.org/10.1038/s41598-01820143-4

26. Senapati $A$ (2013) Managing recurrent pilonidal disease. In: Zbar A, Madoff R, Wexner S (eds) Reconstructive surgery of the rectum, anus and perineum. Springer, London

27. Bali I, Aziret M, Sözen S et al (2015) Effectiveness of Limberg and Karydakis flap in recurrent pilonidal sinus disease. Clinics (Sao Paulo) 70(5):350-355. https://doi.org/10.6061/clinics/2015(05)08

28. Bessa SS (2013) Comparison of short-term results between the modified Karydakis flap and the modified Limberg flap in the management of pilonidal sinus disease: a randomized controlled study. Dis Colon Rectum 56(4):491-498. https:// doi.org/10.1097/DCR.0b013e31828006

29. Ates M, Dirican A, Sarac M, Aslan A, Colak C (2011) Short and long-term results of the Karydakis flap versus the Limberg flap for treating pilonidal sinus disease: a prospective randomized study. Am J Surg 202(5):568-573. https://doi.org/10.1016/j. amjsurg.2010.10.021

30. Ersoy E, Devay AO, Aktimur R, Doganay B, Ozdoğan M, Gündoğdu RH (2009) Comparison of the short-term results after Limberg and Karydakis procedures for pilonidal disease: randomized prospective analysis of 100 patients. colorectal Dis 11(7):705-710. https://doi.org/10.1111/j.14631318.2008.01646.x 
31. Arslan K, Said Kokcam S, Koksal H, Turan E, Atay A, Dogru $O$ (2014) Which flap method should be preferred for the treatment of pilonidal sinus? A prospective randomized study. Tech Coloproctol 18(1):29-37. https://doi.org/10.1007/s10151013-0982-2

32. Bascom J, Bascom T (2007) Utility of the cleft lift procedure in refractory pilonidal disease. Am J Surg 193(5):606-609. https://doi.org/10.1016/j. amjsurg.2007.01.008 (discussion 609)

33. Senapati A, Cripps NPJ, Flashman K, Thompson MR (2011) Cleft closure for the treatment of pilonidal sinus disease. Colorectal Dis 13(3):333-336. https://doi.org/10.1111/j.1463-1318.2009.02148. $x$

34. Rushfeldt C, Bernstein A, Norderval S, Revhaug A (2008) Introducing an asymmetric cleft lift technique as a uniform procedure for pilonidal sinus surgery. Scand J Surg 97(1):77-81 (http://www. ncbi.nlm.nih.gov/pubmed/18450210. Accessed December 14, 2015)

35. Abdelrazeq AS, Rahman M, Botterill ID, Alexander DJ (2008) Short-term and long-term outcomes of the cleft lift procedure in the management of nonacute pilonidal disorders. Dis Colon Rectum 51(7):1100-1106. https://doi.org/10. 1007/s10350-008-9262-z

36. Tezel E, Bostanci H, Anadol AZ, Kurukahvecioglu O (2009) Cleft lift procedure for sacrococcygeal pilonidal disease. Dis Colon Rectum 52(1):135-139. https://doi.org/10.1007/DCR.0b013e31819734f8

37. Guner A, Ozkan OF, Kece C, Kesici S, Kucuktulu U (2013) Modification of the Bascom cleft lift procedure for chronic pilonidal sinus: results in 141 patients. Colorectal Dis 15(7):e402-e406. https:// doi.org/10.1111/codi.12243

38. Ortega PM, Baixauli J, Arredondo Jetal (2014) Is the cleft lift procedure for non-acute sacrococcygeal pilonidal disease a definitive treatment? Longterm outcomes in 74 patients. Surg Today 44(12):2318-2323. https://doi.org/10.1007/ s00595-014-0923-3

39. Favuzza J, Brand M, Francescatti A, Orkin B (2015) Cleft lift procedure for pilonidal disease: technique and perioperative management. Tech Coloproctol 19(8):477-482. https://doi.org/10.1007/s10151015-1333-2

40. Nordon IM, Senapati A, Cripps NPJ (2009) A prospective randomized controlled trial of simple Bascom's technique versus Bascom's cleft closure for the treatment of chronic pilonidal disease. Am J Surg 197(2):189-192. https://doi.org/10.1016/j. amjsurg.2008.01.020

41. Guner A, BozA, Ozkan OF, IleliO, KeceC, ReisE(2013) Limberg flap versus Bascom cleft lift techniques for sacrococcygeal pilonidal sinus: prospective, randomized trial. World J Surg 37(9):2074-2080. https://doi.org/10.1007/s00268-013-2111-9

42. Dudink R, Veldkamp J, Nienhuijs S, Heemskerk J (2011) Secondary healing versus midline closure and modified Bascom natal cleft lift for pilonidal sinus disease. Scand J Surg 100(2):110-113 (http://www.ncbi.nlm.nih.gov/ pubmed/21737387. Accessed December 14, 2015)

43. Keighley MRB (2019) Williams NS Keighley \& Williams' surgery of the anus, rectum and colon, 4th edn. (Two-volume set) CRC press, p 229

44. Boshnaq M, Phan YC, Martini I, Harilingam M, Akhtar M, Tsavellas G (2018) Limberg flap in management of pilonidal sinus disease: systematic review and a local experience. Acta Chir Belg 118(2):78-84. https://doi.org/10.1080/00015458. 2018.1430218
45. Omer Y, Hayrettin D, Murat C, Mustafa Y, Evren D (2015) Comparison of modified limberg flap and modified elliptical rotation flap for pilonidal sinus surgery: a retrospective cohort study. Int J Surg 16(Pt A):74-77. https://doi.org/10.1016/j. ijsu.2015.02.024

46. Akca T, Colak T, Ustunsoy B, Kanik A, Aydin S (2005) Randomized clinical trial comparing primary closure with the Limberg flap in the treatment of primary sacrococcygeal pilonidal disease. $\mathrm{Br} J$ Surg 92(9):1081-1084. https://doi.org/10.1002/ bjs.5074

47. Horwood J, Hanratty D, Chandran P, Billings P (2012) Primary closure or rhomboid excision and Limberg flap for the management of primary sacrococcygeal pilonidal disease? A meta-analysis of randomized controlled trials. Colorectal Dis 14(2):143-151. https://doi.org/10.1111/j.14631318.2010.02473.x

48. Tokac M, Dumlu EG, Aydin MS, Yalcın A, Kilic M (2015) Comparison of modified limberg flap and karydakis flap operations in pilonidal sinus surgery: prospective randomized study. Int Surg 100(5):870-877. https://doi.org/10.9738/ INTSURG-D-14-00213.1

49. Prassas D, Rolfs T-M, SchumacherF-J, Krieg A (2018) Karydakis flap reconstruction versus Limberg flap transposition for pilonidal sinus disease: a meta-analysis of randomized controlled trials. Langenbecks Arch Surg 403(5):547-554. https:// doi.org/10.1007/s00423-018-1697-7

50. Sahebally SM, McMahon G, Walsh SR, Burke JP (2018) Classical Limberg versus classical Karydakis flaps for pilonidal disease- an updated systematic review and meta-analysis of randomized controlled trials. Surgeon. https://doi.org/10.1016/j. surge.2018.07.004

51. Okuş A, Sevinç B, Karahan O, Eryilmaz MA (2012) Comparison of Limberg flap and tension-free primary closure during pilonidal sinus surgery. World J Surg 36(2):431-435. https://doi.org/10. 1007/s00268-011-1333-y

52. Karapolat B, Büyükakıncak S, Kurnaz E, Küçüktülü $\ddot{U}$ (2018) Comparison of limberg flap and oval flap techniques in sacrococcygeal pilonidal sinus disease surgery. Turk J Surg. https://doi.org/10. 5152/turkjsurg.2018.3972

53. Mackowski A, Levitt M (2017) Outcomes of the house advancement flap for pilonidal sinus. ANZ J Surg 87(9):692-694. https://doi.org/10.1111/ans. 13077

54. Fazeli MS, Adel MG, Lebaschi AH (2006) Comparison of outcomes in Z-plasty and delayed healing by secondary intention of the wound after excision of the sacral pilonidal sinus: results of a randomized, clinical trial. Dis Colon Rectum 49(12):1831-1836. https://doi.org/10.1007/s10350-006-0726-8

55. Karakas BR (2013) Comparison of Z-plasty, limberg flap, and asymmetric modified Limberg flap techniques for the pilonidal sinus treatment: review of literature. Acta Chir lugosl 60(3):31-37 (http:// www.ncbi.nlm.nih.gov/pubmed/24669578. Accessed September 16, 2018)

56. Kayal A, Hussain A, Choudhary A, Meghwal A (2014) A comparative study between Karydakis flap reconstruction and double Z-Plasty in patients with sacrococcygeal pilonidal disease. Int Sch Res Notices 2014:523015. https://doi.org/10.1155/ 2014/523015

57. Rao J, Deora H, Mandia R (2015) A retrospective study of 40 cases of pilonidal sinus with excision of tract and Z-plasty as treatment of choice for both primary and recurrent cases. Indian J Surg
77(Suppl 2):691-693. https://doi.org/10.1007/ s12262-013-0983-4

58. DýlekON, Bekereciodlu M(1998) Role of simple V-Y advancement flap in the treatment of complicated pilonidal sinus. Eur J Surg 164(12):961-964. https://doi.org/10.1080/110241598750005147

59. Sahasrabudhe P, Panse N, Waghmare C, Waykole $P$ (2012) V-Y advancement flap technique in resurfacing postexcisional defect in cases with pilonidal sinus disease-study of 25 cases. Indian J Surg 74(5):364-370. https://doi.org/10.1007/ s12262-011-0403-6

60. Koca YS, Yıldız I, Ugur M, Barut I (2018) The V-Y flap technique in complicated and recurrent pilonidal sinus disease. Ann Ital Chir 89:66-69 (http://www. ncbi.nlm.nih.gov/pubmed/29629896. Accessed September 16, 2018)

61. Naveen N, Kumar MK, Babu KR, Dhanraj P (2014) Tandem rhomboid flap repair: a new technique in treatment of extensive pilonidal disease of the natal cleft. JClin Diagn Res 8(9):ND3-ND4. https:// doi.org/10.7860/JCDR/2014/9283.4824

62. Yabanoglu H, Karagulle E, Belli S, Turk E (2015) Results of modified Dufourmentel rhomboid flap in patients with extensive sacrococcygeal pilonidal disease. Acta Chir Belg 114(1):52-57 (http://www. ncbi.nlm.nih.gov/pubmed/24720139. Accessed December 15)

63. Tan AM, Ahmad Z, Loh CY, Gardiner S, Mathur B (2018) A useful alternative surgical technique to reconstructing large defects following excision of recurrent pilonidal sinus disease in the intergluteal region: an operative approach for the transverse lumbar artery perforator flap. Int Wound J 15(4):534-537. https://doi.org/10.1111/iwj.12894 64. Doll D, Luedi MM, Evers T, Kauf P, Matevossian E (2015) Recurrence-free survival, but not surgical therapy per se, determines 583 patients' longterm satisfaction following primary pilonidal sinus surgery. Int J Colorectal Dis 30(5):605-611. https:// doi.org/10.1007/s00384-015-2130-0

65. Di Castro A, Guerra F, Levi Sandri GB, Ettorre GM (2016) Minimally invasive surgery for the treatment of pilonidal disease. The Gips procedure on 2347 patients. Int J Surg 36(Pt A):201-205. https://doi.org/10.1016/j.ijsu.2016.10.040

66. Müller K, Marti L, Tarantino I, Jayne DG, Wolff K, Hetzer FH (2011) Prospective analysis of cosmesis, morbidity, and patient satisfaction following Limberg flap for the treatment of sacrococcygeal pilonidal sinus. Dis Colon Rectum 54(4):487-494. https://doi.org/10.1007/DCR.0b013e3182051d96

67. Yildiz MK, Ozkan E, Odabaşı HM et al (2013) Karydakis flap procedure in patients with sacrococcygeal pilonidal sinus disease: experience of a single centre in Istanbul. ScientificWorldJournal 2013:807027. https://doi.org/10.1155/2013/ 807027

68. Muzi MG, Maglio R, Milito G et al (2014) Long-term results of pilonidal sinus disease with modified primary closure: new technique on 450 patients. Am Surg 80(5):484-488 (http://www.ncbi.nlm. nih.gov/pubmed/24887728. Accessed September 16, 2018)

69. Thompson MR, Senapati A, Kitchen P (2011) Simple day-case surgery for pilonidal sinus disease. $\mathrm{Br} J$ Surg. https://doi.org/10.1002/bjs.7292

70. Lund JN (2017) Less is more in the treatment of pilonidal sinus disease. Dis Colon Rectum 60(1):e1. https://doi.org/10.1097/DCR.0000000000000727

71. Doll D (2017) Pilonidal disease surgery needs more off-midline closure education. World J Surg 41(4):1147-1148. https://doi.org/10.1007/ s00268-016-3809-2 